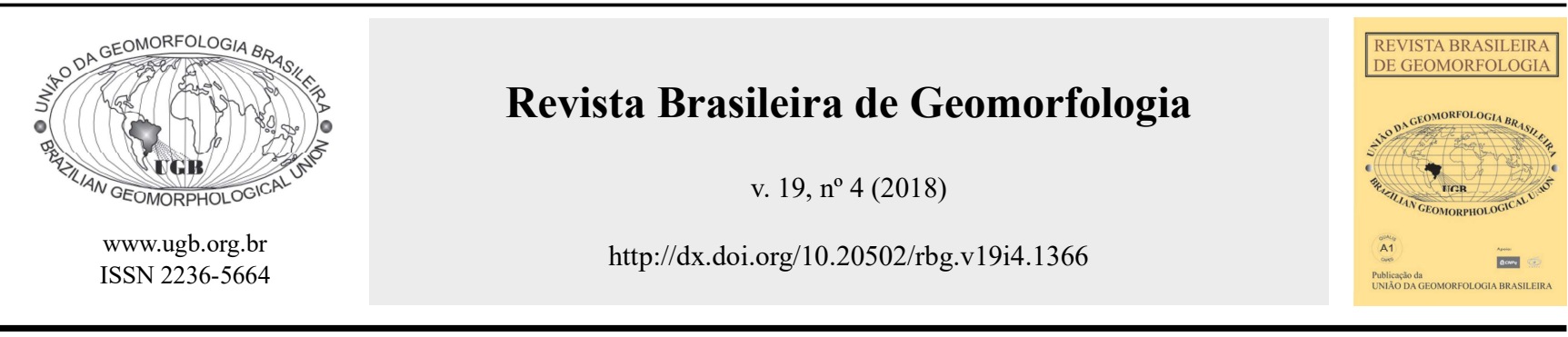

\title{
ESPACIALIDADE E EVOLUÇÃO DA INCISÃO DE VALES FLUVIAIS A PARTIR DA DISSECAÇÃO DO RELEVO NOS DEGRAUS ESCALONADOS DO SUDESTE DE MINAS GERAIS - BRASIL
}

\section{SPATIALITY AND EVOLUTION OF THE INCISION OF RIVER VALLEYS FROM THE RELIEF DISSECTION IN THE STAGGERED STEPS OF THE SOUTHEAST OF MINAS GERAIS - BRAZIL}

Breno Ribeiro Marent
Departamento de Geografia, Universidade Federal de Minas Gerais
Av. Antônio Carlos, 6627, Belo Horizonte, Minas Gerais. CEP: 31.270-901. Brasil

E-mail: brenomarent@gmail.com

Roberto Célio Valadão

Departamento de Geografia, Universidade Federal de Minas Gerais Av. Antônio Carlos, 6627, Belo Horizonte, Minas Gerais. CEP: 31.270-901. Brasil

E-mail:valadaobh@gmail.com

Luiz Augusto Manfré

Departamento de Engenharia de Transportes, Universidade de São Paulo Av. Professor Almeida Prado, Travessa 2, 83, São Paulo, São Paulo. CEP: 05508-070. Brasil E-mail: luizmanfre@gmail.com

Rodrigo Affonso de Albuquerque Nóbrega

Departamento de Cartografia, Universidade Federal de Minas Gerais Av. Antônio Carlos, 6627, Belo Horizonte, Minas Gerais. CEP: 31.270-901. Brasil

E-mail: raanobrega@ufmg.br

Informações sobre o Artigo

Recebido (Received):

21/12/2017

Aceito (Accepted):

09/08/2018

Palavras-chave:

Dissecação Fluvial; Bacia Hidrográfica; Denudação Continental.

\section{Keywords:}

Fluvial Dissection; Hydrographic Basin; Continental Denudation.

\section{Resumo:}

A configuração geomorfológica do sudeste de Minas Gerais é marcada por degraus escalonados em nítida conformação com a rede hidrográfica regional. A organização em planta destes degraus acompanha a distribuição espacial das bacias hidrográficas que drenam a área investigada. As bacias do interior continental, Paraná e São Francisco, localizam-se em degrau superior, enquanto as bacias costeiras se situam em distintos níveis topográficos, de tal modo que a bacia do rio Doce ocupa patamar intermediário e a do Paraíba do Sul degrau inferior. É atribuída a estas últimas maior capacidade denudacional em razão de sua maior amplitude altimétrica e por estarem elas diretamente atreladas ao nível de base geral do oceano. O presente trabalho investigou a dissecação e evolução espacial dos vales fluviais nos distintos compartimentos geomorfológicos em que se inserem esses conjuntos de bacias. Foi aqui empregado método de investigação da dissecação do relevo e da incisão dos vales fluviais apoiado em 
técnicas de geoprocessamento e na análise de atributos geocartográficos. Essas técnicas consistiram no uso de dados de elevação altimétrica para se calcular a declividade, a curvatura vertical das vertentes e a densidade de drenagem, parâmetros quantitativos fundamentais na elaboração de mapa de incisão dos vales fluviais. Os resultados demostraram que a evolução dos vales fluviais está fortemente condicionada aos diferentes graus de incisão da rede hidrográfica, evidenciando maior incisão nas bacias costeiras em comparação às bacias interiores. Nas bacias costeiras a incisão vertical mais efetiva da rede hidrográfica resultou no significativo encaixamento dos vales e, consequentemente, no seu gradiente e amplitude altimétrica mais elevados e no estreitamento de seus flancos. Tal condição geomorfológica, na área investigada, favorece a instalação de processos desestabilizadores das vertentes, uma vez que sua dinâmica se vincula no espaço e no tempo ao ritmo e vigor da dissecação fluvial. Por outro lado, naquelas bacias interiores a menor amplitude altimétrica dos vales favorece o seu entulhamento por sedimentos que transitam nas calhas fluviais.

\begin{abstract}
:
The geomorphological configuration of the southeast of Minas Gerais is made according to staggered steps. The spatial organization of these steps closely accompanies the spatial distribution of the hydrographic basins of the area investigated in this work, such that the upper step is drained by the basins of the Paraná and São Francisco rivers (inland basins) and the lower by the river basins Doce and Paraíba do Sul (coastal basins). The coastal basins present greater denudational capacity because of their greater altimetric amplitude and because they are directly linked to the general base level of the ocean. The present work investigated the dissection and spatial evolution of the fluvial valleys in the different geomorphological compartments in which these sets of basins are inserted. A research method was used to investigate the dissection of the relief and incision of the river valleys supported by geoprocessing techniques and the analysis of geocartographic attributes. The results showed that the evolution of the river valleys is conditioned by the different degrees of incision of the hydrographic network and that the incision is larger in the coastal basins. This condition is a relevant explanatory factor regarding the recurrence of stream piracy already recognized in the geomorphological literature, which are responsible for the incorporation of stretches of the inland basins to those coastal basins. In the coastal basins, the most effective vertical incision of the hydrographic network resulted in the significant deepening of the valleys and, consequently, in their higher altimetric gradient and amplitude and in the narrowing of their flanks. This geomorphological condition in the area investigated favors the installation of destabilizing processes of the slopes, since its dynamics is linked in space and time to the rhythm and force of the incision of the hydrographic network. In these interior basins the lower altimetric amplitude of the valleys favors the accumulation of sediments that are transported in the fluvial channels.
\end{abstract}

\section{Introdução}

A porção sudeste do estado de Minas Gerais é constituída por três patamares que se organizam, em planta e perfil, na forma de degraus topográficos escalonados cuja espacialidade acompanha aquela das bacias hidrográficas presentes nessa região (CHEREM et al., 2012; 2013; MARENT; VALADÃO, 2015). Entre estes patamares ocorrem escarpas que, também, individualizam as principais bacias hidrográficas, a saber: as bacias dos rios Paraná e São Francisco em um patamar altimétrico superior; a bacia do rio Doce, que ocupa um patamar intermediário; e a bacia do rio Paraíba do Sul em um patamar inferior. Cherem et al. (2012) e Salgado et al. (2012), mediante investigação de taxas de denudação $\left({ }^{10} \mathrm{Be}\right)$, verificaram que as bacias hidrográficas altimetricamente posicionadas nos patamares inferiores estão se propagando em direção às bacias que ocupam o patamar superior através da erosão remontante mais intensa de suas cabeceiras situadas nas escarpas em relação ao planalto imediatamente acima. Salgado et al. (2012) e Cherem et al. (2013) reconheceram nessas porções as capturas fluviais como principal processo na evolução do relevo e das bacias hidrográficas. Estes eventos seriam controlados pelo nível de base mais baixo dos degraus topográficos em posição altimétrica inferior que se encontram nas bacias costeiras.

Marent e Valadão (2015) reconheceram nessa área um Grande Escarpamento que divide bacias costeiras (Doce e Paraíba do Sul) e interioranas (São Francisco 


\section{Espacialidade e Evolução da Incisão de Vales Fluviais a partir da Dissecação do Relevo}

e Paraná). Estas bacias estão sujeitas a distintos níveis de base compreendidos, de um lado, pelo oceano e, de outro, por grandes canais fluviais que drenam o interior continental. Em outras porções do Brasil oriental marcadas pela presença desse Grande Escarpamento, Valadão (2009) e Salgado et al. (2014) verificaram o rejuvenescimento do relevo proveniente do nível de base mais baixo das bacias costeiras. Configuração semelhante foi identificada em outras porções do globo por Thomas e Summerfield (1987), Gilchrist e Summerfield (1990), Ollier e Pain (1997) e Gilchrist et al. (1994). É nesse contexto que se insere este trabalho, cujo objetivo é analisar a organização espacial da dissecação fluvial vigente em bacias interiores e costeiras do sudeste mineiro, bem como averiguar seus reflexos na evolução dos vales. Apesar do reconhecido avanço das bacias costeiras em direção ao interior continental (CHEREM et al., 2012, SALGADO et al., 2012) e da ocorrência de vales suspensos (MARENT e VALADÃO, 2015) e capturas fluviais (CHEREM et al., 2013), até o presente momento não havia sido investigado o comportamento da dissecação dos vales e nem mesmo sua evolução mediante o avanço continente adentro das bacias costeiras.

Diante do exposto, a relevância deste estudo se vincula às investigações voltadas para a geomorfogênese de áreas continentais adjacentes a margens passivas, cuja organização topográfica inclui a presença de escarpas. Segundo a literatura especializada, estas áreas têm sua dinâmica condicionada, de início, à formação de ressaltos topográficos associados a flancos de riftes que, mais tarde, em fase pós-rifte, recuam continente adentro graças à atuação de uma vaga erosiva. Originase daí um Grande Escarpamento que separa bacias hidrográficas costeiras daquelas interiores; as primeiras altimetricamente posicionadas acima da referida escarpa e, as últimas, imediatamente abaixo dela. No caso da região aqui investigada, esse Grande Escarpamento constitui elemento fisiográfico notório do sudeste mineiro, mas não é ele único. Outro escarpamento está presente nessa área e sua abrangência espacial é marcadamente coincidente com os limites das bacias hidrográficas que ocupam posição costeira.

A área de estudo situa-se no sudeste do estado de Minas Gerais, entre os paralelos $20^{\circ} 35^{\prime}$ e $21^{\circ} 35^{\prime} \mathrm{S}$ e meridianos $42^{\circ} 30^{\prime}$ e $44^{\circ} 15^{\prime} \mathrm{W}$ (Figura 1). É representada pelas bacias do alto rio Paraopeba (bacia do São Francisco), do alto rio Grande (bacia do Paraná), do alto rio Doce e do rio Pomba (bacia do Paraíba do Sul).
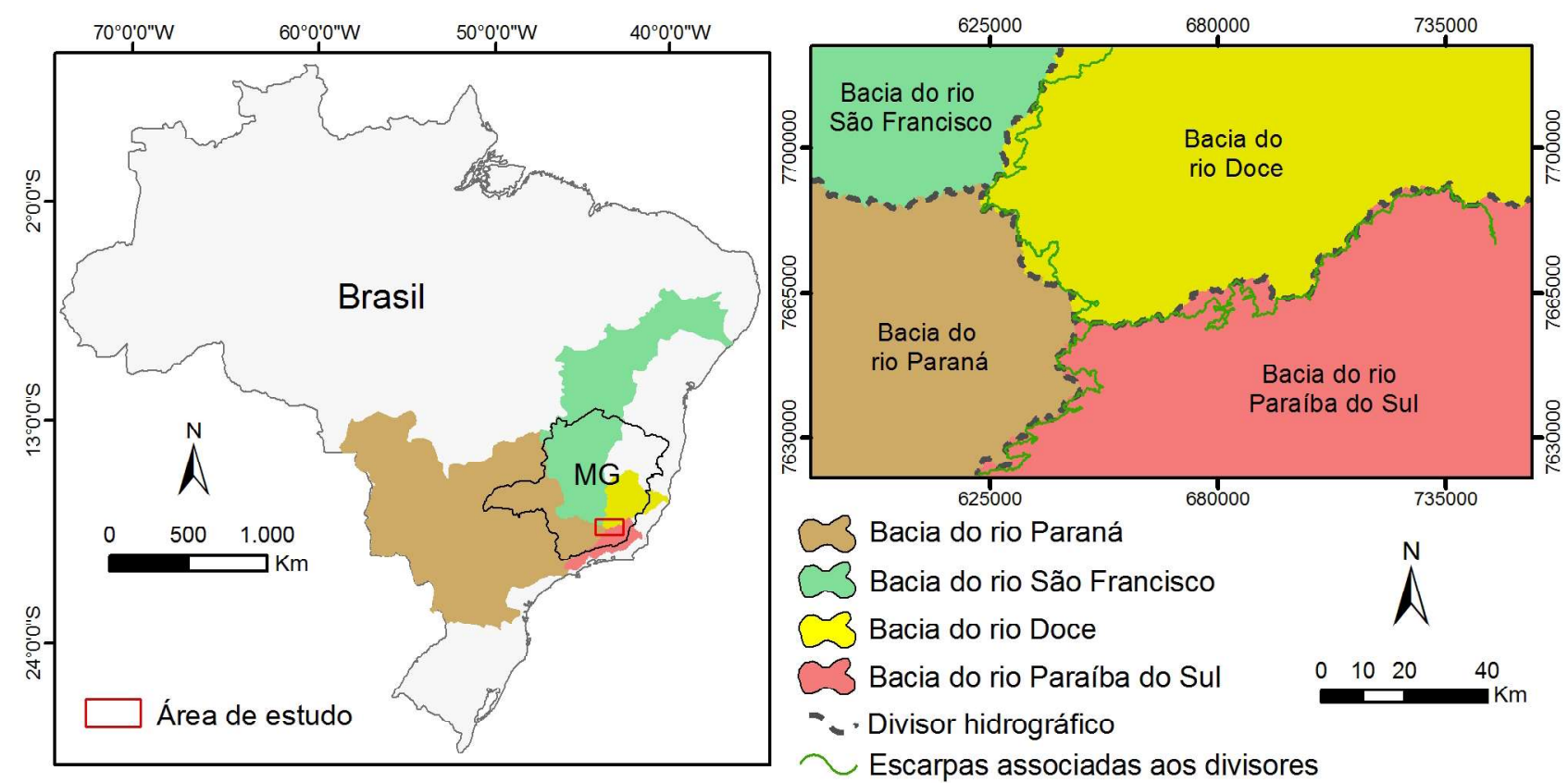

Figura 1 - Localização da área de estudo segundo distribuição espacial das bacias hidrográficas dos rios São Francisco, Paraná, Doce e Paraíba do Sul no território brasileiro. Observe que as bacias do Paraná e São Francisco apresentam grandes extensões e ocupam posição interior, contrastando sobremaneira com a extensão mais reduzida das bacias do Doce e Paraíba do Sul, as quais drenam diretamente para o oceano e ocupam posição costeira. 


\section{Materiais e Métodos}

A dissecação do relevo ou rugosidade topográfica foi inicialmente utilizada no país em procedimentos de mapeamento geomorfológico do Projeto RADAMBRASIL, mediante proposta de matriz que contempla índices de dissecação (BARBOSA et al., 1984). Posteriormente, Ross (1992) baseado nos trabalhos deste projeto propôs novos valores para as classes dessa matriz. Ambos procedimentos empregaram técnicas manuais no reconhecimento dos parâmetros investigados. Com o objetivo de criar ferramenta capaz de quantificar, classificar e delimitar as unidades de relevo em ambiente automatizado, Sampaio (2008) propôs o cálculo do Índice de Concentração de Rugosidade (ICR). Esse autor adotou como referencial de análise a distribuição espacial da declividade (medidas indiretas da inclinação e do tamanho das vertentes) entendida como padrões de rugosidade, de tal modo que os níveis de dissecação do relevo pudessem ser uniformemente mapeados para uma mesma área. Os trabalhos de Souza e Sampaio (2010), Messias e Trovó (2013) e Sampaio e Augustin (2014) aplicaram o ICR em diferentes áreas, sendo então reconhecida sua eficácia aos interesses da investigação geomorfológica.

Na elaboração do mapa de dissecação do relevo da área investigada foi empregado procedimento metodológico distinto daqueles utilizados pelos autores já citados anteriormente. Optou-se pela elaboração de mapa de incisão da rede hidrográfica cuja centralidade são os vales fluviais, sua geometria e inserção no quadro geomorfológico em que se expressam. Esse mapa foi construído segundo procedimento desenvolvido por Manfré et al. (2015) com vistas à compartimentação do relevo regional, empregando-se SRTM da base Topodata (INPE, 2011). Para o processo de segmentação foram utilizadas a elevação numérica (ZN), declividade $(\mathrm{SN})$, curvatura vertical $(\mathrm{VN})$, curvatura horizontal $(\mathrm{HN})$, e a densidade de drenagem (DD) (Figura 2).

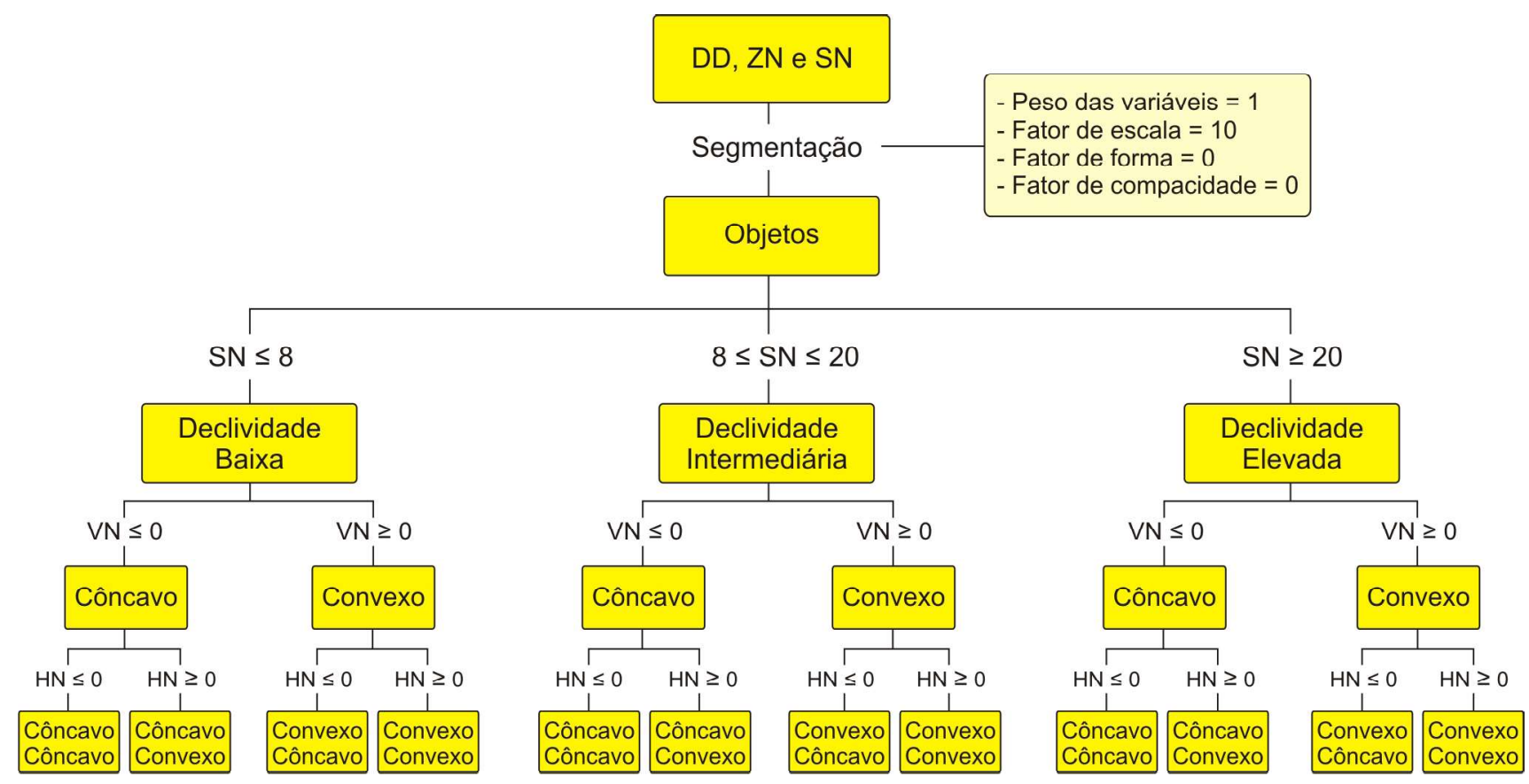

Figura 2 - Esquema de árvore de decisão com base nas informações de elevação (média e desvio padrão) e suas derivações. DD: densidade de drenagem, ZN: elevação numérica, $S N$ : declividade, VN: curvatura vertical e HN: curvatura horizontal.

O uso desses dados e informações segue o pressuposto da subdivisão do relevo natural e tenta tornar mais evidente as características topográficas (VALERIANO, 2003; VALERIANO e CARVALHO JÚNIOR, 2003). A segmentação foi executada conforme Dragut e Eisank (2012), baseada no processo de classificação OBIA (Object-based Image Analysis), ajustando-se fatores de forma e de compacidade para zero, eliminando-se, assim, os efeitos de quaisquer formas definidas sobre os objetos de imagem. Para preservar os parâmetros de análise, um fator de escala 10 foi usado, o que permitiu a distinção de pequenas 
áreas homogêneas do relevo.

A elevação é elemento base a partir do qual foram obtidas as demais variáveis geomorfológicas. $\mathrm{Na}$ classificação empregada a declividade foi considerada como primeiro nível, de acordo com as classes definidas pelo IBGE (2009), a saber: até $8 \%$ baixa; entre 8 e $20 \%$ intermediária; acima de $20 \%$ elevada. Para o segundo nível foram definidas classes segundo a forma da curvatura horizontal (côncava ou convexa). Para o terceiro nível, a curvatura vertical foi utilizada para o estabelecimento das classes finais, também de acordo com sua forma (côncava ou convexa). Segundo Valeriano (2008), a curvatura horizontal expressa a forma da vertente quando observada em projeção horizontal, tendo a percepção em planta do caráter divergente ou convergente das linhas de fluxo (Figura 3). Por sua vez, a curvatura vertical expressa a forma da vertente observada em perfil, tendo-se a percepção do caráter do terreno.

O mapa de dissecação, uma vez elaborado segundo as curvaturas vertical e horizontal, foi empregado no reconhecimento de atributos morfométricos dos vales fluviais, como áreas dissecadas segundo diferentes declividades e altimetrias, o que favoreceu e possibilitou sobremaneira o desenvolvimento de demais produtos dele derivados. Como a curvatura vertical expressa a forma da vertente observada em perfil, foi ela interpretada como resultado da incisão do canal fluvial durante a abertura de seu vale. No caso do presente trabalho, a produção de mapa de incisão vertical dos vales fluviais associada a técnicas cartográficas permitiram gerar esquema preliminar de evolução dos vales nos distintos compartimentos geomorfológicos da área investigada. Este mapa foi elaborado mediante adoção daqueles procedimentos já empregados anteriormente (dissecação do relevo; Figura 2), excluindo-se a curvatura horizontal e utilizando-se as seguintes variáveis: curvatura vertical, declividade e densidade de drenagem. Contudo, o segmento retilíneo não foi exibido, uma vez que as concavidades e convexidades das vertentes se apresentaram adequadas para a execução da análise. Naqueles ensaios em que o segmento retilíneo foi contemplado, registrou-se considerável ruído nas imagens produzidas, o que comprometeu sobremaneira os resultados.

\section{Curvatura vertical}
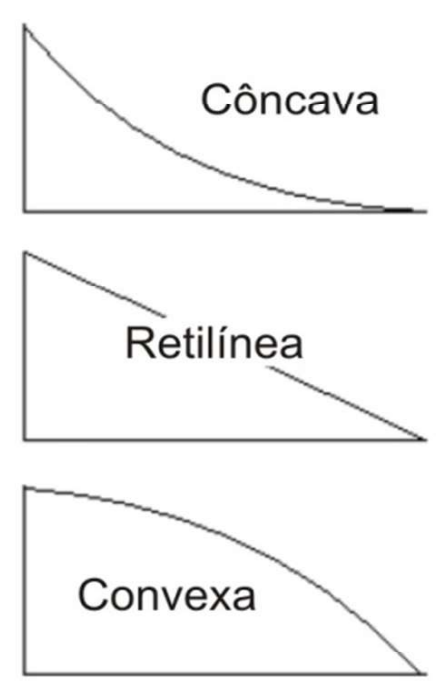

Curvatura horizontal

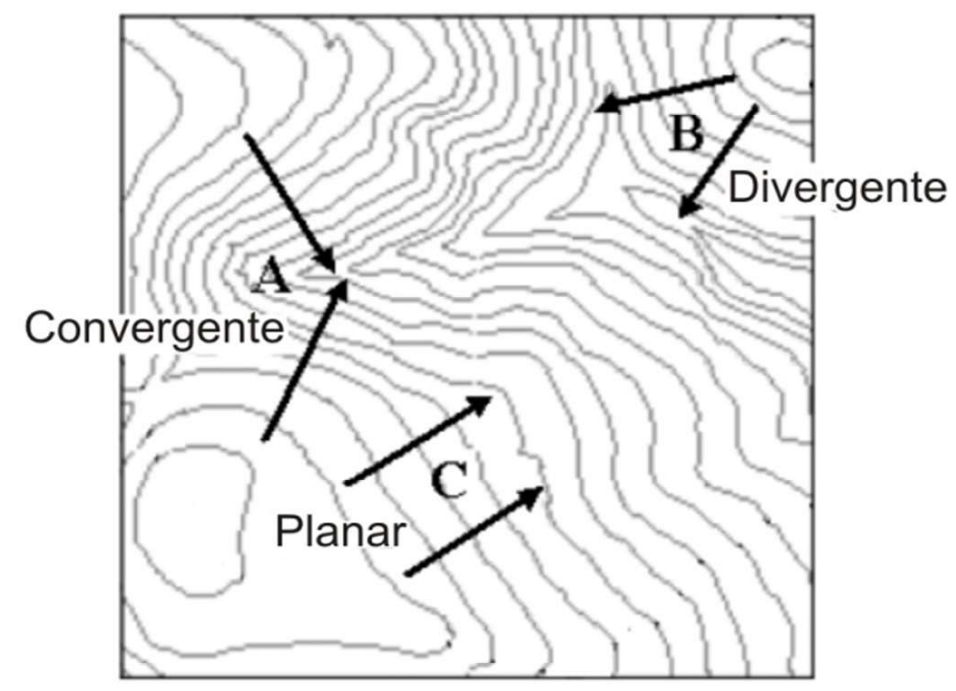

Figura 3 - Representação esquemática das curvaturas vertical (em perfil) e horizontal (em planta). Fonte: Valeriano (2008).

A partir do mapa de incisão dos vales fluviais, que exibe visão em planta, foram selecionadas áreas-alvo com o intuito de serem representativas dos distintos estágios a que os vales fluviais estiveram submetidos, em escala local, à evolução regional da área (Figura 4). Nestas áreas-alvo cada segmento (côncavo/convexo) foi medido dentro das diferentes declividades e organizado juntamente com as amplitudes médias dessas porções em perfil representativo (Figura 5). Estas amplitudes foram calculadas a partir de cartas topográficas do IBGE, na escala 1:50.000, de modo a se obter os perfis transversais aos vales. Acredita-se que a sequência de perfis produzida segundo distintos domínios geomorfológicos revelou uma possível evolução espaço-temporal dos vales fluviais na área de estudo (Figura 6). 


\section{Resultados e Discussões}

O mapa de incisão dos vales fluviais forneceu visão em planta de manchas homogêneas de áreas mais e menos dissecadas segundo suas porções côncavas e convexas, distinguindo-se claramente os principais domínios geomorfológicos na área investigada (Figura 4). Esse mapa fornece elementos que permitem estabelecer a evolução dos vales fluviais, segundo os compartimentos geomorfológicos em que se encontram inseridos (Figura 5). Na composição desse mapa as vertentes foram compartimentadas em segmentos côncavos e convexos; as porções retilíneas não foram incluídas no intuito de se evitar um detalhamento excessivo que comprometesse a análise. Tal procedimento foi tentado, mas o resultado final gerou um mapa que inviabilizou a análise para a escala adotada. Esses segmentos foram divididos de acordo com a declividade da vertente, agrupada a partir de IBGE (2009): incisão baixa para declividades inferiores a $8 \%$; incisão média para declividades entre 8 e $20 \%$; e incisão alta para declividades acima de $20 \%$. Os segmentos de baixa declividade, inferiores a $8 \%$, se situam em topos de morros mais suavizados nas porções convexas, enquanto as porções côncavas encontram-se, em geral, naqueles eixos fluviais constituídos pelas planícies de inundação e terraços recentes. Os segmentos de média declividade, entre 8 e $20 \%$, correspondem nas porções côncavas às áreas situadas adjacente e altimetricamente acima dos fundos de vale constituídos pelos segmentos de baixa declividade $(<8 \%)$ e, também, às áreas de fundo de vale cuja dissecação imprimiu maior incisão da ordem de 8 a $20 \%$. As porções convexas, entre 8 e $20 \%$, correspondem a áreas situadas adjacente e altimetricamente abaixo dos interflúvios constituídos pelos segmentos de baixa declividade $(<8 \%)$ e, também, às áreas de topos de morro cuja dissecação imprimiu incisão que fomentou maior inclinação aos mesmos, entre 8 e $20 \%$. Por sua vez, naqueles segmentos de alta declividade, acima de $20 \%$, as porções côncavas localizam-se adjacente e altimetricamente acima dos segmentos côncavos de média declividade e, também, nas áreas situadas em fundos de vales cujo aprofundamento foi capaz de produzir maior encaixamento do relevo ( $>20 \%)$. As porções convexas, acima de $20 \%$, correspondem às áreas situadas adjacente e altimetricamente abaixo dos topos de morro de média declividade ( 8 a 20\%) e, também, às áreas situadas em topos de morros mais íngremes cujos vales sofreram elevado processo de encaixamento ( $>20 \%)$.

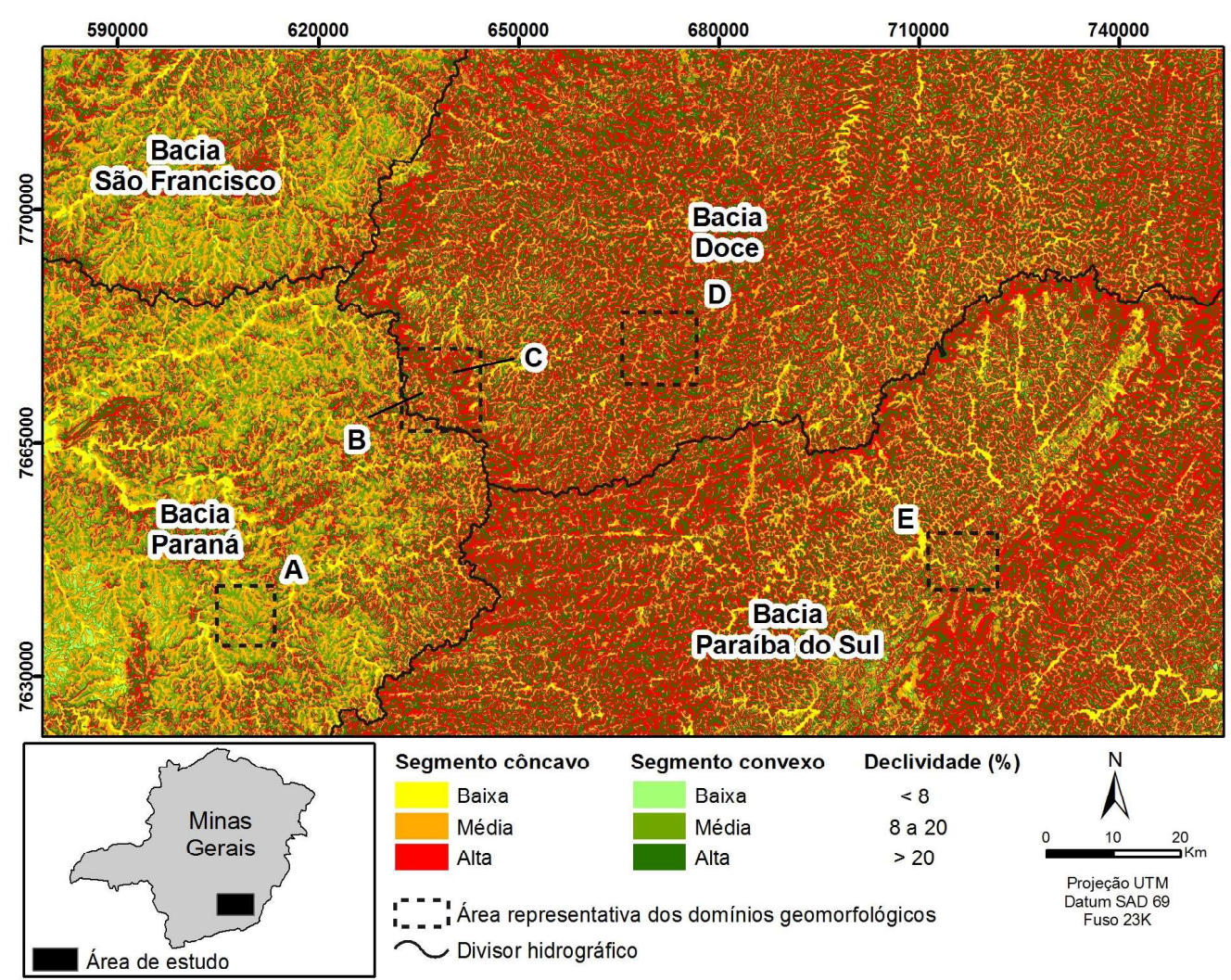

Figura 4 - Mapa de incisão dos vales fluviais, com indicação de áreas representativas dos diferentes domínios geomorfológicos selecionados para elaboração dos perfis transversais dos vales. 


\section{Espacialidade e Evolução da Incisão de Vales Fluviais a partir da Dissecação do Relevo}

Omapa de incisão dos vales fluviais exibe dois padrões distintos principais. O primeiro, posicionado segundo as bacias do interior continental, exibe aprofundamento predominantemente médio do relevo. O segundo, posicionado nas bacias costeiras, mostra aprofundamento mais elevado do relevo quando comparado às bacias do interior continental. Esse comportamento da morfologia dos vales fluviais vigente em ambos conjuntos de bacias decorre, ao que tudo indica, da maior dissecação registrada nas bacias voltadas diretamente para o oceano, como consequência de ajustes ao nível de base geral, conforme mencionado por Thomas e Summerfield (1987), Gilchrist e Summerfield (1990), Gilchrist et al. (1994), Ollier e Pain (1997), Valadão (1998; 2009) e Salgado et al. (2014).
Com o objetivo de se compreender a evolução espaço-temporal dos vales fluviais na área investigada, foram selecionadas áreas-alvo capazes de fornecer indicadores geomorfológicos de elevada significância que abrangessem a diferenciação contrastante manifesta no relevo. Essas áreas-alvo se localizam nos seguintes domínios geomorfológicos (Figuras 4 e 5): (A) degrau superior; (B) área de captura fluvial; (C) área de captura fluvial em estágio avançado de evolução; (D) degrau intermediário; e (E) degrau inferior. Nessas áreas-alvo, as distâncias das faixas relativas às concavidades $\mathrm{e}$ convexidades foram extraídas e inseridas em perfis transversais, de modo a representar o comprimento médio das vertentes.
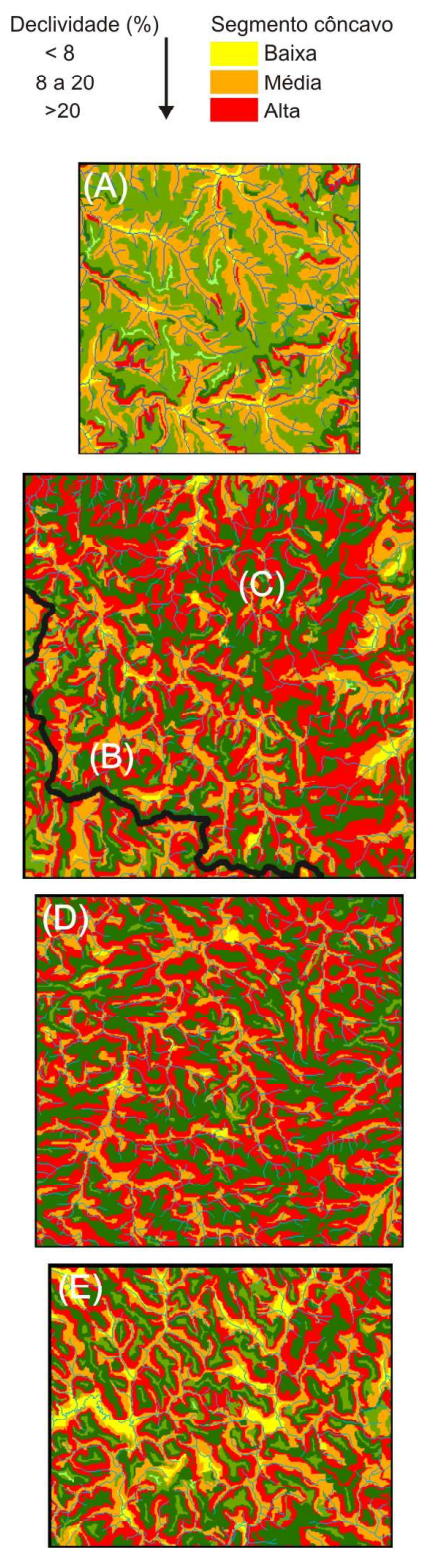
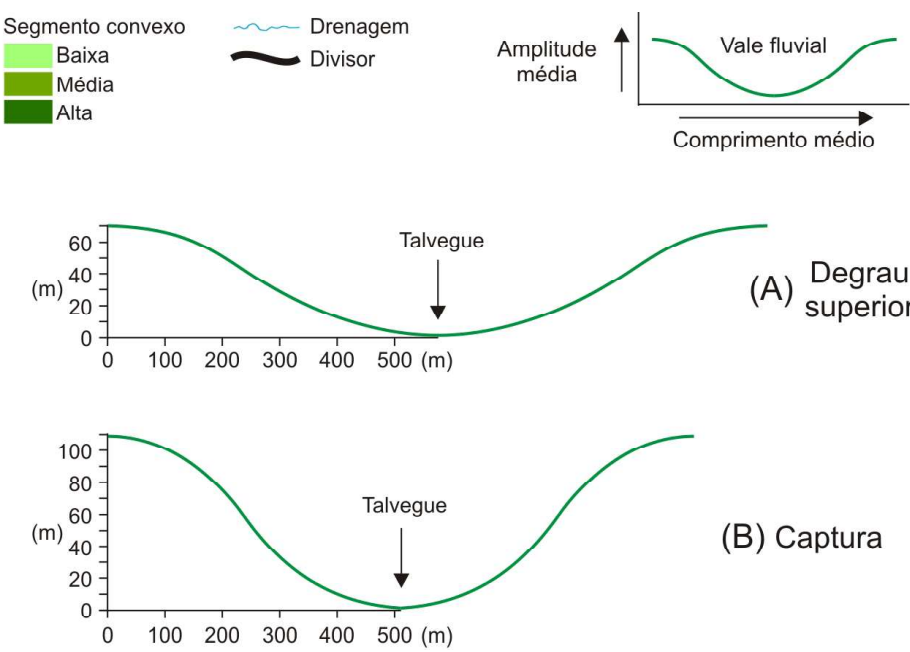

(B) Captura

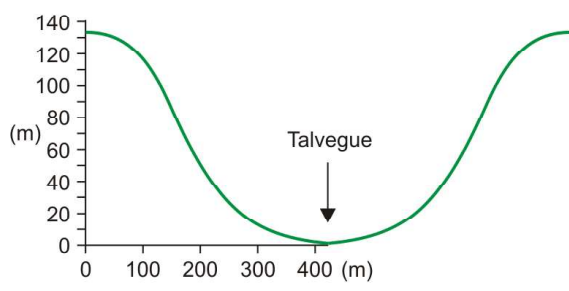

(C) Captura
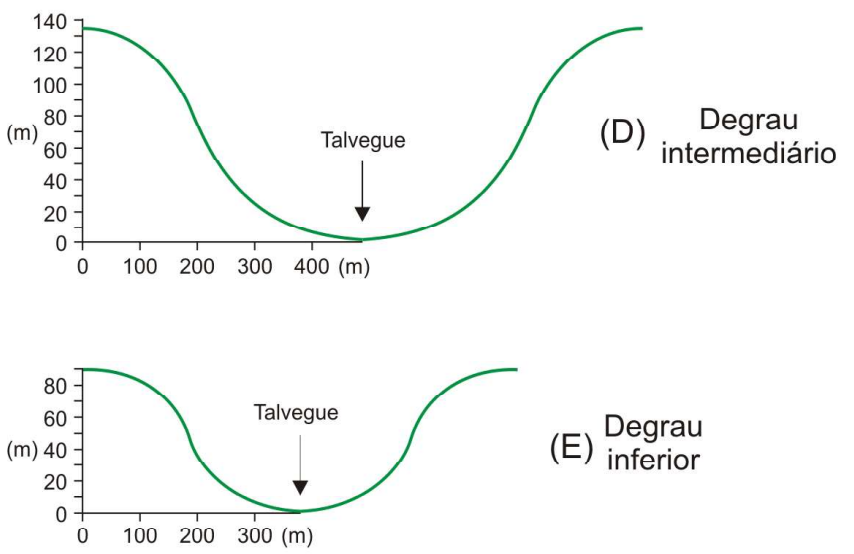

(E) $\begin{aligned} & \text { Degrau } \\ & \text { inferior }\end{aligned}$

Figura 5 - Áreas-alvo representativas dos domínios geomorfológicos do sudeste mineiro, selecionadas segundo mapa de incisão fluvial. Para cada área-alvo são apresentados os respectivos perfis transversais de seus vales. 
A primeira área-alvo é representativa do degrau superior onde há predomínio de aprofundamento médio dos vales, com declividades entre 8 e $20 \%$ (Figura 5 - A). Esta incisão dos canais fluviais ocorre na maior parte das bacias dos rios Paraná e São Francisco, que drenam em direção ao interior continental (Figura 4). Entretanto, porções localizadas nestas bacias podem exibir aprofundamento elevado dos vales com declividades acima de $20 \%$. O perfil transversal de seus vales mostra, em geral, amplitudes médias de $70 \mathrm{~m}$ e comprimento médio das vertentes de $580 \mathrm{~m}$. Aárea-alvo seguinte na sequência evolutiva corresponde à captura fluvial do rio Piranga (Figura 5-B), já investigada por Salgado et al. (2012) e Cherem et al. (2013). Localiza-se a NE do divisor hidrográfico (linha preta contínua, na Figura 5) que separa as bacias dos rios Paraná e Doce e a SW da escarpa (marcada por polígonos maiores de cor verde e vermelha). Nesta área há maior incisão dos vales fluviais, os quais exibem aprofundamento médio de $110 \mathrm{~m}$ e comprimento médio da vertente de $500 \mathrm{~m}$. Adjacente à captura anterior (Figura 4 - B) encontrase área-alvo que é aqui interpretada como captura em processo mais avançado de ajuste ao novo nível de base (Figura 4-C), devido ao seu contexto geomorfológico. Esta área é constituída por vales suspensos posicionados acima da escarpa que drenam em direção ao degrau intermediário junto à bacia do rio Doce. Esta área-alvo exibe aprofundamento médio mais acentuado dos vales (135 m) e comprimento médio das vertentes de $420 \mathrm{~m}$, portanto se mostram mais íngremes e mais encaixados (Figura 5-C).

Na sequência evolutiva, a área-alvo seguinte está inteiramente inserida no degrau intermediário, na bacia do rio Doce (Figura 4-D). Entretanto, a incisão desses vales também pode ser encontrada no degrau inferior, na bacia do Paraíba do Sul. O perfil destes vales revela amplitude média de $135 \mathrm{~m}$ e comprimento médio das vertentes de $480 \mathrm{~m}$ (Figura 5 - D). A última área-alvo encontra-se no degrau inferior, onde ocupa uma faixa alongada de direção NE-SW na bacia do rio Paraíba do Sul (Figura 4 - E) e, também, trechos restritos na bacia do rio Doce. Nesta área-alvo são menores tanto o aprofundamento médio dos vales (cerca de $90 \mathrm{~m}$ ), quanto o comprimento médio das vertentes $(380 \mathrm{~m}$; Figura $5-\mathrm{E}$ ).
As diferentes áreas-alvo investigadas viabilizaram reconhecer uma possível evolução espaço-temporal dos vales fluviais, que contempla a articulação entre as bacias interioranas e costeiras. No degrau superior os vales que drenam em direção ao interior continental se mostram mais amplos e menos profundos, provavelmente em decorrência de seu ajuste mais efetivo ao nível de base local de seus principais rios (Figura $6-\mathrm{A}$ ). Os cursos fluviais maiores tendem a exibir extensas áreas de acumulação aluvial (Figura 4). Após a captura fluvial a área antes pertencente à bacia interiorana passa a fazer parte da bacia costeira na condição de vale suspenso, o qual passa estar submetido a novo nível de base (Figura 4). Isto resulta na maior incisão vertical do vale que se torna mais profundo e estreito (Figura 6 -B). À medida que a área capturada é denudada e gradativamente incorporada à superfície inferior, o aprofundamento do vale aumenta, bem como seu encaixamento, tornando o vale mais estreito (Figura $6-\mathrm{C}$ ). $\mathrm{O}$ aumento da declividade e amplitude facilita a desestabilização das encostas para os processos modeladores de vertente que acabam por alargar o vale, mas mantém sua profundidade (Figura 6-D). Neste estágio o vale já se encontra integralmente inserido no degrau posicionado abaixo da escarpa.

As etapas B, C e D representadas na Figura 6 se assemelham às fases evolutivas de vales formados pela incisão vertical da rede hidrográfica em um planalto, tal como descrito por Seild et al. (1996) para escarpas adjacentes a margens passivas elevadas. A última fase exibe a redução da amplitude das vertentes pela denudação e entulhamento dos fundos de vale (Figura $6-$ E). Essa fase sugere o início de ajustamento com o nível de base local marcado por vales entulhados de sedimentos. Nesta área, na bacia do rio Paraíba do Sul, Oliveira et al. (2014) identificaram nos principais cursos fluviais fundos de vale com espessas sequências aluviais acumuladas em terraços fluviais e planícies de grandes extensões. Esta faixa de acumulação aluvial chega localmente a ultrapassar os $500 \mathrm{~m}$ de largura nos cursos fluviais principais (polígonos em amarelo claro), notadamente nos segmentos côncavos de baixa incisão fluvial (Figura. 4). Esses autores também relacionaram os fundos de vale amplos à estabilidade do nível de base. 
(A) $\mathrm{T}=0$

(B) $\mathrm{T}=1$

(C) $\mathrm{T}=2$

(D) $T=3$

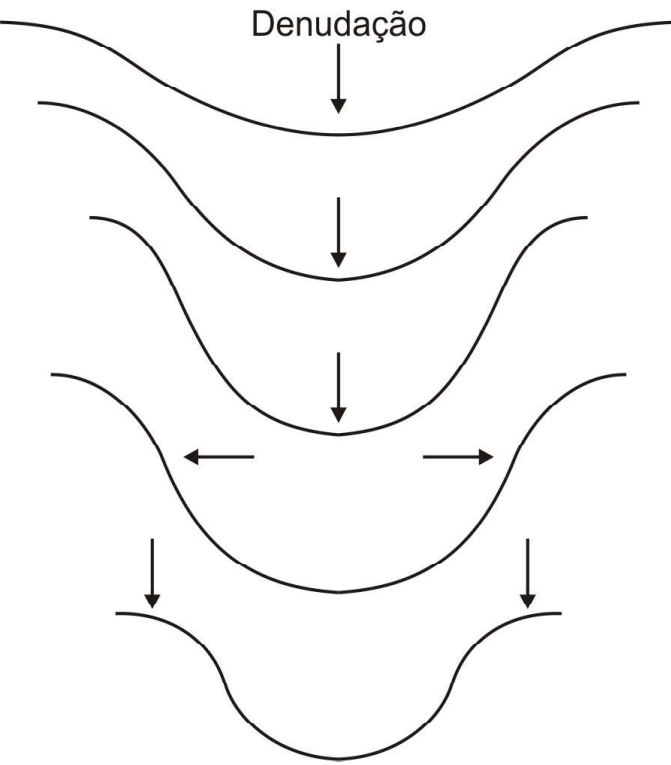

Degrau superior

Captura fluvial

Captura avançada

Degrau intermediário

Degrau inferior

Figura 6 - Etapas têmporo-espaciais de evolução dos vales fluviais que figuram nos degraus escalonados do sudeste mineiro. A dimensão espaço-temporal transcorre na sequência $T=0$ a $T=4$. Observe que as setas verticais nos tempos $T=0$ a $T=2$ enfatizam a maior intensidade da incisão vertical da rede hidrográfica, ao passo que, em $T=4$ elas dão ênfase ao predomínio do processo de rebaixamento vertical dos interflúvios; as setas horizontais representam o relevante papel do processo de retração lateral dos flancos dos vales em $T=3$.

\section{Considerações Finais}

O presente trabalho reconhece e caracteriza diferentes graus de dissecação da rede de drenagem vigentes nos domínios costeiro e interiorano de bacias hidrográficas do sudeste mineiro. As distintas morfologias dos vales fluviais relacionadas a essas bacias estão fortemente condicionadas ao menor ou maior vigor da incisão da rede hidrográfica, com destaque para as bacias costeiras que se revelaram mais vigorosas energeticamente, graças aos ajustes de seu nível de base ao oceano. A tamanha magnitude desse vigor energético acabou por imprimir no sudeste mineiro uma organização geomorfológica peculiar, expressa hoje pela ocorrência de degraus escalonados de extensão regional seccionados e delimitados por proeminentes escarpamentos. A expansão areal das bacias costeiras ao longo do tempo decorreu, ao que tudo indica, do processo de penetração de uma vaga erosiva continente adentro, a qual foi aqui morfometricamente caracterizada mediante emprego de geotecnologias. Nesta expansão das bacias costeiras foram reconhecidas etapas evolutivas que se entrelaçam no tempo e no espaço, etapas estas comandadas por variações nas taxas de incisão da rede hidrográfica, como também pelo reafeiçoamento do conjunto de vertentes por ela drenada. No transcorrer destas etapas, imediatamente após a ocorrência de capturas fluviais naqueles trechos localizados nos rebordos dos degraus altimetricamante mais elevados (na porção superior das escarpas), verifica-se a incisão dos vales mais efetiva. A drenagem passa a exibir forte encaixamento combinado ao alto gradiente de seu perfil longitudinal, o que resulta na maior amplitude das vertentes e no consequente estreitamento dos vales. Tais fatos aumentam a deflagração de processos desestabilizadores de vertente que acabam por favorecer a ampliação areal dos vales. Uma vez mais ajustada ao novo nível de base, ditado pelo oceano, a drenagem cria as condições de seu entulhamento aluvial, o que reduz a amplitude das vertentes.

A evolução espaço-temporal das bacias hidrográficas através da articulação de diferentes escalas espaciais evidencia nítido controle do curso fluvial como nível de base na evolução das vertentes, em escala local. Em escala regional, esse estudo também demonstra que o nível de base geral exibe a capacidade de influenciar na dinâmica local dessas vertentes, de modo a alterar o potencial energético das bacias costeiras capaz de gerar um efeito retroalimentador que reestrutura o modelado a montante, até que seja alcançada uma condição de equilíbrio. Tal fato tem implicações no aumento de processos erosivos e movimentos de massa que podem fomentar o assoreamento dos canais fluviais 
e a consequente transferência de sedimentos para as bacias oceânicas.

\section{Agradecimentos}

Os autores agradecem a CAPES (Coordenação de Aperfeiçoamento de Pessoal de Nível Superior) pela bolsa de doutorado concedida ao primeiro autor; ao Programa de Pós-Graduação em Geografia da UFMG pelo custeio das atividades de campo que viabilizaram a pesquisa.

\section{Referências Bibliográficas}

BARBOSA, G.V.; SILVA, T.C.; NATALI FILHO, T.; DEL'ARCO, D.M.; COSTA, R.C.R. Evolução da metodologia para mapeamento geomorfológico do projeto RADAMBRASIL. Boletim Técnico Projeto RADAMBRASIL. Série Geomorfologia, n. 1, 187p. 1984.

CHEREM, L.F.S.; VARAJÃO, C.A.C.; BRAUCHER, R.; BOURLÉS, D.; SALGADO, A.A.R.; VARAJÃO, A.C. Longterm evolution of denudational escarpments in southeastern Brazil. Geomorphology, 173-174, p. 118-127, 2012. DOI: https://doi.org/10.1016/j.geomorph.2012.06.002

CHEREM, L.F.S.; VARAJÃO, C.A.C.; BRAUCHER, R.; BOURLÈS, D.; SALGADO, A.A.R.; VARAJÃO, A.C. O papel das capturas fluviais na morfodinâmica das bordas interplanálticas do sudeste do Brasil. Revista Brasileira de Geomorfologia, v. 14, n. 4, p. 299-308, 2013. DOI: http://dx.doi. org/10.20502/rbg.v14i4.325

DRAGUT, L.; EISANK, C. Automated object-based classification of topography from SRTM data. Geomorphology, v. 141-142, n. 1, p. 21-33, 2012. DOI: https://doi.org/10.1016/j. geomorph.2011.12.001

GILCHRIST, A.R.; SUMMERFIELD, M.A. Differential denudation and flexural isostasy in formation of riftedmargin upwarps. Nature, v. 346, p.739-742, 1990. DOI: $10.1038 / 346739 \mathrm{a} 0$

GILCHRIST, A.R.; KOOI, H.; BEAUMONT, C. PostGondwana geomorphic evolution of southwestern Africa: implications for the controls on landscape development from observations and numerical experiments. Journal of Geophysical Research, v. 99, n. B6, p. 12,211-12,228, 1994. DOI: $10.1029 / 94 J B 00046$

IBGE - Instituto de Geografia e Estatística. Manual Técnico de Geomorfologia. Coordenação de Recursos Naturais e Estudos Ambientais. 2 ${ }^{\mathrm{a}}$ Ed. Rio de Janeiro: IBGE, 2009. 182 p. Disponível em: <https://biblioteca.ibge.gov.br/visualizacao/ livros/liv66620.pdf>. Acesso em: $19 \mathrm{dez} 2017$.

INPE - Instituto de Pesquisa Espaciais. TOPODATA - Banco de Dados Geomorfométricos do Brasil. 2011. Disponível em: $<$ http://www.dsr.inpe.br/topodata $>$. Acesso em: 26 jul 2012.

MANFRÉ, L.A.; NÓBREGA, R.A.A.; QUINTANILHA, J.A. Regional and local topography subdivision and landform mapping using SRTM-derived data: a case study in southeastern Brazil. Environmental Earth Sciences (Internet), v. 73, p. $6457-$ 6475, 2015. Disponível em: <https://www.springerprofessional. de/regional-and-local-topography-subdivision-and-landformmapping-u/11840556>. Acesso em: 13 set 2016.

MARENT, B.R.; VALADÃO, R.C. Compartimentação geomorfológica dos planaltos escalonados do sudeste de Minas Gerais - Brasil. Revista Brasileira de Geomorfologia, v.16, n. 2, p. 255-270, 2015. DOI: http://dx.doi.org/10.20502/rbg.v16i2.634

MESSIAS, C.G.; TROVÓ, D.F.G. Dissecação do relevo do setor nordeste da carta topográfica de São José dos Campos: uma comparação entre os métodos de mapeamento manual e índice de concentração de rugosidades. In: ENCONTRO DE GEÓGRAFOS DA AMÉRICA LATINA, 14., 2013, Lima Perú. Anais... Lima - Perú: [s.n], 2013. 11 p.

OLIVEIRA, L.A.F.; MAGALHÃES JUNIOR, A.P.; LIMA, L.B.S.; CARVALHO, A. Fatores condicionantes da configuração de fundos de vale colmatados na bacia do alto-médio rio Pomba, leste de Minas Gerais. Revista Brasileira de Geomorfologia, v. 15 , n. 4, p. 639-657, 2014. DOI: http://dx.doi.org/10.20502/ rbg.v15i4.494

OLLIER, C.D.; PAIN, C.F. Equating the basal unconformity with the palaeoplain: a model for passive margins. Geomorphology, 19, p. 1-15, 1997. DOI: https://doi.org/10.1016/S0169$555 \mathrm{X}(96) 00048-7$

ROSS, J.L.S. O registro cartográfico dos fatos geomórficos e a questão da taxonomia do relevo. Revista do Departamento de Geografia, n. 6, p. 17-29, 1992. DOI: http://dx.doi.org/10.7154/ RDG.1992.0006.0002

SALGADO, A.A.R.; SOBRINHO, L.C.G.; CHEREM, L.F.S.; VARAJÃO, C.A.C.; BOURLÈS, D.; BRAUCHER, R.; MARENT, B.R. Estudo da evolução da escarpa entre as bacias do Doce/Paraná em Minas Gerais através da quantificação das taxas de desnudação. Revista Brasileira de Geomorfologia, v. 13, n.2, p. 213-222, 2012. DOI: http://dx.doi.org/10.20502/ rbg.v13i2.280

SALGADO, A.A.R.; MARENT, B.R.; CHEREM, L.F.S.; BOURLÈS, D.; SANTOS, L.J.C.; BRAUCHER, R.; BARRETO, H.N. Denudation and retreat of the Serra do Mar escarpment in 
southern Brazil derived from in situ-produced ${ }^{10} \mathrm{Be}$ concentration in river sediment. Earth Surface Progress and Landforms. 39, 311-319, 2014. DOI: 10.1002/esp.3448

SAMPAIO, T.V.M. Parâmetros morfométricos para melhoria da acurácia do mapeamento da rede de drenagem - uma proposta baseada na análise da Bacia Hidrográfica do Rio Benevente - ES. Tese (Doutorado em Geografia). Instituto de Geociências, Universidade Federal de Minas Gerais, Belo Horizonte. 2008. 142p.

SAMPAIO, T.V.M.; AUGUSTIN, C.H.R.R. Índice de Concentração da Rugosidade: uma nova proposta metodológica para o mapeamento e quantificação da dissecação do relevo como subsídio a cartografia Geomorfológica. Revista Brasileira de Geomorfologia, v. 15, n. 1, p. 47-60, 2014. DOI: http://dx.doi. org/10.20502/rbg.v15i1.376

SEILD, M.A.; WEISSEL, J.K.; PRATSON, L.F. The kinematics and pattern of escarpment retreat across the rifted continental margin of SE Australia. Basin Research. 12, p. 301-316, 1996. DOI: $10.1046 /$ j.1365-2117.1996.00266.x

SOUZA, L.F.; SAMPAIO, T.V.M.; Aplicação do Índice de Concentração da Rugosidade à identificação de classe de dissecação do relevo: uma proposta de quantificação e automatização em ambiente SIG. In: SIMPÓSIO BRASILEIRO DE CIÊNCIAS GEODÉSICAS E TECNOLOGIAS DA GEOINFORMAÇÃO, 3., 2010, Recife. Anais... Recife: [s.n], 2010. 7 p.

THOMAS, M.F.; SUMMERFIELD, M.A. Long-term landform development: key themes and research problems. In: GARDINER, V. International Geomorphology. Edited by: Jonh Wiley \& Sons Ltd., part II, 1987. p: 935-956.

VALADÃO, R.C. Evolução de longo-termo do relevo do Brasil Oriental (desnudação, superfícies de aplainamento e soerguimentos crustais). Tese (Doutorado em Geologia). Instituto de Geociências, Universidade Federal da Bahia. Salvador. 1998. 243 p.

VALADÃO, R.C. Geodinâmica de Superfícies de Aplainamento, desnudação continental e tectônica ativa como condicionantes da megageomorfologia do Brasil Oriental. Revista Brasileira de Geomorfologia, v. 10, n. 2, p. 77-90, 2009. DOI: http://dx.doi. org/10.20502/rbg.v10i2.132

VALERIANO, M.M. Curvatura vertical de vertentes em microbacias pela análise de modelos digitais de elevação. Revista Brasileira de Engenharia Agrícola e Ambiental, v. 7, n. 3, p. 539-546, 2003. Disponível em: <http://www.scielo.br/ pdf/rbeaa/v7n3/v7n3a22.pdf >. Acesso em: 19 out 2014.

VALERIANO, M.M. Topodata: guia para utilização de dados Geomorfológicos locais. São José dos Campos: INPE, 2008. 72p. Disponível em: <http://mtc-m16c.sid.inpe.br/col/sid.inpe. br/mtc-m18@80/2008/07.11.19.24/doc/publicacao.pdf $>$.Acesso em: 19 out 2014 .

VALERIANO, M.M.; CARVALHO JÚNIOR, O.A. Geoprocessamento de modelos digitais de elevação para mapeamento da curvatura horizontal em microbacias. Revista Brasileira de Geomorfologia, v. 4, n. 1, p. 17-29, 2003. 